\title{
Peningkatan Kualitas Hidup Lansia "Personal Hygiene dan Penyakit Degeneratif pada Lansia" di Desa Sugihrejo, Kecamatan Kawedanan, Kabupaten Magetan
}

\author{
*1Riska Ratnawati, ${ }^{1}$ Retno Widiarini, ${ }^{2}$ Yeni Utami \\ ${ }^{1}$ Program Studi Kesehatan Masyarakat, Sekolah Tinggi Kesehatan \\ Bhakti Husada Mulia Madiun, Indonesia \\ 2Program DIII Kebidanan Sekolah Tinggi Ilmu Kesehatan \\ Bhakti Husada Mulia Madiun, Indonesia
}

\begin{abstract}
ABSTRAK
Personal hygiene merupakan kebutuhan dasar yang meliputi perawatan kulit, mandi, perawatan mulut, perawatan mata, hidung, telinga, perawatan rambut, serta perawatan kaki dan kuku. Kebutuhan personal hygiene harus menjadi prioritas utama bagi lansia karena dengan personal hygiene yang baik membuat lansia memiliki resiko rendah untuk mengalami penyakit infeksi, pada mata dan telinga. Adapun gambaran perilaku personal hygiene lansia yang harus dipenuhi, yaitu merupakan kebutuhan dasar yang meliputi perawatan kulit, mandi, perawatan mulut, perawatan mata, hidung, telinga, perawatan rambut, serta perawatan kaki dan kuku. Personal hygiene senantiasa harus terpenuhi $k$ arena merupakan tindakan pencegahan primer yang spesifik untuk meminimalkan mikroorganisme bakteri yang pada ahirnya mencegah seseorang terkena penyakit Kebutuhan personal hygiene harus menjadi prioritas utama bagi lansia karena dengan personal hygiene yang baik membuat lansia memiliki resiko yang rendah untuk mengalami penyakit infeksi, pada mata dan telinga.
\end{abstract}

\section{PENDAHULUAN}

Perubahan fisik lansia akan mempengaruhi tingkat kemandirian. Kemandirian adalah kebebasan untuk bertindak, tidak tergantung pada orang lain tidak terpengaruh pada orang lain dan bebas mengatur diri sendiri atau aktivitas seseorang baik individu maupun kelompok dan berbagai kesehatan atau penyakit (Orem, 2001) menggambarkan lansia sebagai suatu unit yang juga menghendaki kemandirian dalam mempertahankan hidup, kesehatan dan kesejahteraannya. Faktor yang mempengaruhi tingkat kemandirian lansia dalam melakukan aktifitas kehidupan sehari-hari, seperti usia, mobilitas dan mudah jatuh (Nugroho, 2008) lain dan bebas mengatur diri sendiri atau aktivitas seseorang baik individu maupun kelompok dan berbagai kesehatan atau penyakit (Orem, 2001) menggambarkan lansia sebagai suatu unit yang juga menghendaki kemandirian dalam mempertahankan hidup, kesehatan dan kesejahteraannya. Faktor yang mempengaruhi tingkat kemandirian lansia dalam melakukan aktifitas kehidupan sehari-hari, seperti usia, mobilitas dan mudah jatuh (Nugroho, 2008).

Status kesehatan lansia tidak terlihat dari status fungsional, dengan pengertian dalam kemampuan seseorang menjalankan aktifitasnya sehari- hari secara sehat. Konsep ini terintegrasi dalam tiga domain utama, yaitu fungsi biologis, psikologis (kognitif dan afektif) serta sosial. Salah satu komponen 
psikologis dalam diri individu, yaitu fungsi kognitif yang meliputi perhatian, persepsi, berpikir, pengetahuan dan daya. Kemandirian dalam mengurus diri sendiri pada lansia dapat dinilai dari kemampuannya melakukan aktivitas sehari-hari tanpa pengawasan, pengarahan, atau bantuan orang lain seperti mandi, berpakaian rapi, pergi ke toilet dan melakukan sendiri aktivitas disana, berpindah tempat (berpindah dari lantai ke kursi, dari kursi ke tempat tidur, berjalan, naik dan turun tangga, dapat mengontrol buang air besar dan kecil (tidak beser), dan dapat makan sendiri dengan baik (misalnya makanan tidak berserakan disekitarnya). Salah satu kriteria orang mandiri adalah dapat mengaktualisasikan dirinya (self actualized) tidak menggantungkan kepuasankepuasan utama pada lingkungan dan kepada orang lain. Mereka lebih tergantung pada potensipotensi mereka sendiri bagi perkembangan dan kelangsungan pertumbuhannya ingat (Alfina Shofia, 2009).

\section{METODE}

Perencanaan kegiatan dimulai dengan survei lapangan oleh tim pengabdian. Survei lapangan dilakukan oleh tim pengabdian. Tim pengabdian melakukan diskusi dengan kepala desa, bidan desa dan kader posyandu lansia. Pada diskusi ini tim pengabdian mengindentifikasi permasalahan yang dihadapi oleh lansia. Permasalahan yang ditemukan adalah rendahnya pengetahuan masyarakat mengenai kualitas hidup lansia, promosi kesehatan lansia hanya terbatas pada senam tiap hari minggu, dan kurangnya prasarana di posyandu lansia. Kemudian tim pengabdian menawarkan beberapa solusi untuk menyelesaikan masalah tersebut. Solusi yang ditawarkan adalah memberikan edukasi kepada masyarakat lansia mengenai kualitas hidup pada lansia dan cara-cara yang dapat dilakukan agar masyarakat dapat hidup di usia senja dengan berkualitas, cara melakukan aktivitas fisik lansia di rumah, dan peningkatan prasarana posyandu lansia dengan membuat taman tanaman obat.

Perencanaan kegiatan dimulai dengan survei lapangan oleh tim pengabdian. Survei lapangan dilakukan oleh tim pengabdian . Permasalahan yang ditemukan adalah rendahnya pengetahuan masyarakat mengenai kualitas hidup lansia, promosi kesehatan lansia hanya terbatas pada senam tiap hari minggu, dan kurangnya prasarana di posyandu lansia. Kemudian tim pengabdian menawarkan beberapa solusi untuk menyelesaikan masalah tersebut. Solusi yang ditawarkan adalah memberikan edukasi kepada masyarakat mengenai kualitas hidup pada lansia dan cara-cara yang dapat dilakukan agar masyarakat dapat hidup di usia senja dengan berkualitas, cara melakukan aktivitas fisik lansia di rumah, dan peningkatan prasarana posyandu lansia dengan membuat taman tanaman obat dan pemberian bantuan tensimeter dengan kualitas baik. Tahap kedua merupakan pelaksanaan kegiatan pengabdian berupa solusi yang telah disetujui berupa kegiatan sosialisasi program Kesehatan lansia dan pengukuran tensi. Sosialisasi bertujuan untuk a pengetahuan lansia tentang personal hygiene lansia masih sangat kurang.

Secara garis besar teknis Pelaksanaan Kegiatan Pengabdian adalah sebagai berikut: 1. Persiapan. Pada tahap persiapan ini dilakukan untuk mengidentifikasi adanya masalah pada tempat pengabdian. kegiatan yang telah dilakukan dapat memberikan solusi bagi permasalahan. Selain itu di tahap awal ini juga akan dilakukan sosialisasi program pada wilayah pengabdian. 2. Pelaksanaan 
kegiatan. Pelaksanaan kegiatan meliputi kegiatan penyuluhan tentang kesehatan lansis. 3. Evaluasi dan monitoring kegiatan. Evaluasi dan monitoring kegiatan dilakukan pada awal pelaksanaan, proses dan akhir pelaksanaan kegiatan.

\section{HASIL DAN PEMBAHASAN}

Pelaksanaan kegiatan pengabdian berupa solusi yang telah disetujui Bersama antara kepala desa, bidan desa, kader posyandu lansia dan para lansia di Desa Sugihrejo, Kecamatan Kawedanan, Kabupaten Magetan kegiatan sosialisasi program Kesehatan lansia dan pengukuran tensi. Sosialisasi bertujuan untuk a pengetahuan lansia tentang personal hygiene lansia masih sangat kurang. Dalam kegiatan ini juga melibatkan mahasiswa Prodi Kesehatan Masyarakat.

Kegiatan dengan memberikan edukasi kesehatan lansia kepada masyarakat desa Sidorejo. Materi edukasi yang diberikan mencakup aktivitas yang perlu dilakukan oleh lansia agar memiliki kualitas hidup yang baik. Materi yang diberikan adalah penyakit yang sering ditemukan pada lansia dan cara hidup sehat di usia lanjut. Materi ini juga mencakup zat gizi dan sumber makanannya yang diperlukan oleh lansia sehingga memenuhi kebutuhan gizi lansia dan kondisi kesehatan lansia tetap terjaga.

Materi lainnya adalah aktivitas fisik yang perlu dilakukan oleh lansia. Pada lansia banyak dari organ-organ tubuh yang mulai mengalami proses degenerasi. Terjadi penurunan massa otot serta kekuatannya, laju denyut jantung maksimal, kapasitas aerobik, dan terjadinya peningkatan lemak tubuh. Bukti-bukti yang ada menunjukkan bahwa latihan dan olahraga pada lansia dapat mencegah atau melambatkan kehilangan fungsional tersebut, bahkan latihan yang teratur dapat memperbaiki kesakitan dan kematian yang diakibatkan oleh penyakit kardiovaskuler. Untuk menghindari faktor-faktor risiko yang ada, terutama sebagai pencegahan dari berbagai penyakit degeneratif harus dilakukan sehingga tujuan usia lanjut yang disebut "menua sehat" dapat tercapai.

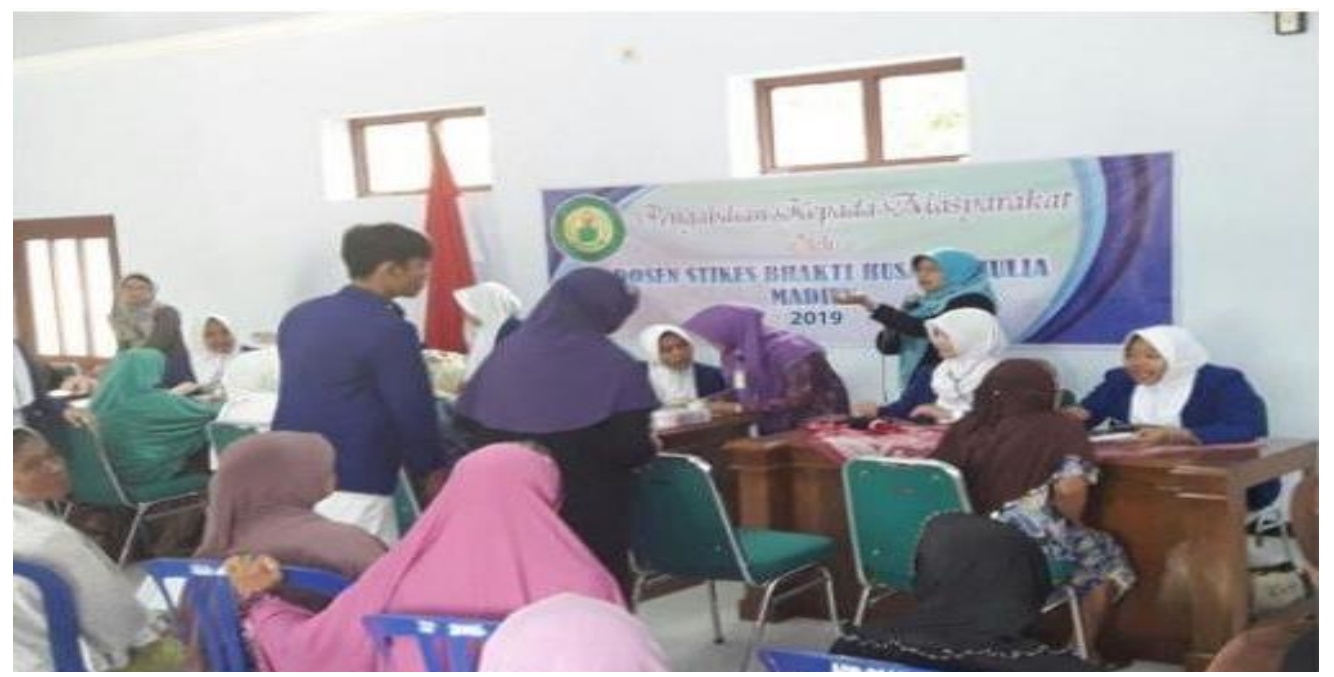

Gambar 1

Sosialisasi Edukasi Kesehatan Lansia 


\section{Pembahasan}

Hasil pelaksanaan penyuluhan tentang tentang Kesehatan lansia yang sudah dilaksanakan ini, dapat dievaluasi: (1) Data Subyektif, yang didapat seperti: Lansia yang mengajukan pertanyaan dapat memahami dan mengerti mengenai jawaban yang telah diberikan oleh penyuluh; (2) Data obyektif, yang didapat seperti: Jumlah peserta penyuluhan 32 orang (100\%) hal ini menunjukkan sebagian besar Lansia dari yang direncanakan sejumlah 32vorang, mengikuti penyuluhan tentang kesehatan lansia.

Ada 5 lansia yang aktif (Pak Sarkam, Bu Milah, Bu Sukinem, Pak Badirun dan Bu Purwati) mengajukan pertanyaan dalam kegiatan penyuluhan kesehatan lansia utamanya terkait dengan penyakit-penyakit yang sering muncul pada usia lansia dan bagaimana cara mengatasinya. Tujuan kegiatan yaitu meningkatkan pengetahuan lansia tentang personal Hygiene lansia, sehingga perlu dilaksanakan peningkatan pengetahuan di waktu yang lain atau dengan cara yang lain selain penyuluhan kesehatan. Sebagai tindak lanjut perlu diberikan lagi peningkatan pengetahuan tentang personal hygiene dan penyakit degenerative oleh Kader posyandu maupun pihak lain sesuai dengan kompetensinya.

\section{SIMPULAN}

Telah dilakukan kegiatan pengabdian kepada masyarakat berbasis prodi oleh Prodi S1 Kesehatan Masyarakat, Stikes Bhakti Husada Mulia Madiun. Kegiatan pengabdian berjudul Peningkatan Kualitas Hidup Lansia "Personal Hygiene dan Penyakit degenerative pada lansia Melalui Kegiatan pengabdian dilaksanakan selama dua hari diharapakan pengetahuan lansia meningkat dan dapat mengaplikasikan dalam kehidupan sehari-harinya.

\section{DAFTAR PUSTAKA}

Herdywinoto, S. (2005). Menjaga Keseimbangan Kualitas Hidup Para Lanjut Usia. Jakarta: PT Gamedia Pustaka Umum.

Maryam, R. S., Ekasari, M. F., Rosidawati., Jubaedi, A., \& Batubara, I. (2008).

Mengenal usia lanjut dan perawatanya. Jakarta: Salemba Medika.

Nugroho, W. (2008). Keperawatan gerontik dan geriatrik. Edisi dua. Jakarta: EGC.

Notoatmodjo, S. (2003). Promosi Kesehatan \& Ilmu Perilaku. Jakarta: PT Rineka Cipta

Notoatmodjo, S. (2007). Promosi Kesehatan \& Ilmu Perilaku. Jakarta: Rineka Cipta.

Notoatmodjo, S. (2005). Metodologi penelitian kesehatan. Jakarta: PT Rineka Cipta.

Santoso, H., \& Ismail, H. (2009). Memahami krisis lanjut usia: uraian medis dan pedagogis-pastoral. Cet.1. Jakarta: Gunung Mulia. 
Lampiran 1. Dokumentasi kegiatan
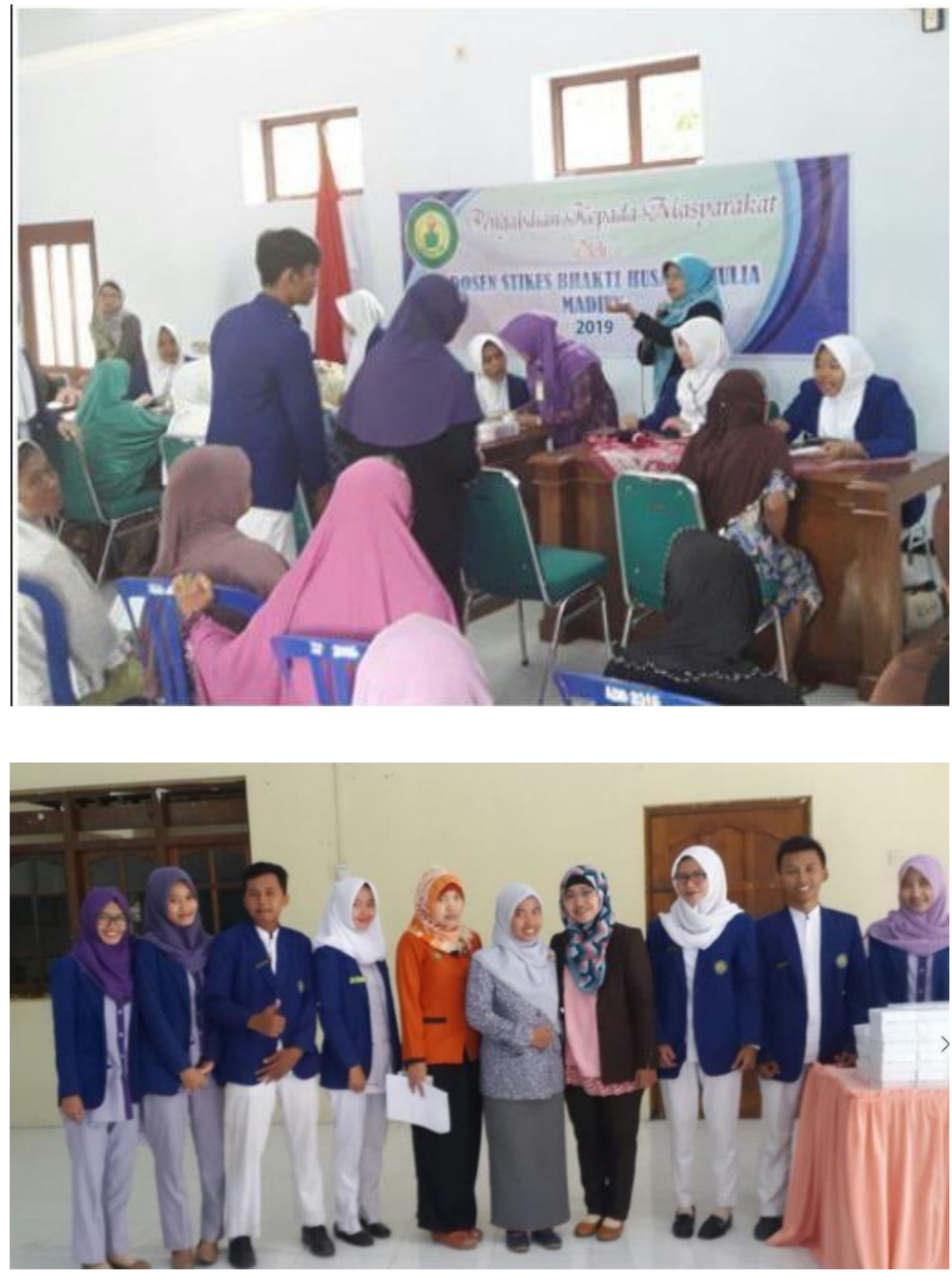

Lampiran 2. Materi Penyuluhan

Personal Higiene

\section{KEBERSIHAN MULUT DAN GIGI DIJAGA DENGAN :}

1. Untuk yang masih mempunyai gigi :

Menyikat gigi secara teratur sekurang-kurangnya dua kali dalam sehari, pagi hari dan malam sebelum tidur, termasuk bagian gusi dan lidah. Bila ada gigi berlubang, sebaiknya segera ke Puskesmas. Bila tetap ada endapan warna kuning sampai cokelat, kirim ke Puskesmas/dokter gigi.

2. Bagi yang menggunakan gigi palsu :

Gigi dibersihkan dengan sikat gigi perlahan-lahan di bawah air yang mengalir. Bila perlu dapat digunakan pasta gigi. Pada waktu tidur, gigi tiruan/palsu tidak dipakai dan direndam dalam air bersih. 
3. Bagi mereka yang tidak mempunyai gigi sama sekali :

Setiap habis makan juga harus menyikat bagian gusi dan lidah untuk membersihkan sisa makanan yang melekat.

\section{KEBERSIHAN KEPALA, RAMBUT DAN KUKU :}

1. Cuci rambut secara teratur paling sedikit dua kali seminggu untuk menghilangkan debu dan kotoran yang melekat di rambut dan kulit kepala.

2. Potong kuku secra teratur.

\section{KEBERSIHAN TEMPAT TIDUR :}

1. Tempat tidur harus selalu dibersihkan. Kasur yang cekung ditengah hendaknya dibalik setiap kali bila tempat tidur dibersihkan. Juga kasur harus dijemur ditengah terik matahari.

\section{KEBERSIHAN KULIT (MANDI) :}

Usaha untuk membersihkan kulit dapat dengan cara mandi setiap hari secara teratur, paling sedikit dua kali sehari. Pada saat mandi lansia sebaiknya mempergunakan air hangat untuk merangsang peredaran darah dan mencegah kedinginan, menggunakan

\section{KEBERSIHAN MATA :}

Elastisitas lensa mata pada lanjut usia berkurang. Akibatnya, tulisan yang kecil menjadi kabur pada jarak normal, tapi jadi terang bila jarak didekatkan.

Gejala yang tak normal antara lain :

- Penglihatan menjadi ganda

- Bintik hitam atau ada daerah yang gelap

- Sakit pada mata

- Terlihat ada warna atau terang di sekitar ujung-ujung objek

- Mata yang kemerahan

- Tiba-tiba kehilangan kemampuan melihat dengan jelas

Bila ada gejala-gejala ini, harus segera mengkonsultasikan diri ke dokter. Setiap dua tahun mata harus dikontrol, bila tidak ada kelainan.

Tidak usah menunggu sampai dua tahun bila ada kelainan-kelainan seperti :

- Kesulitan membaca

- Memasukkan benang ke lubang jarum

- Kesulitan membaca nomor bus dan lain-lain

Sabun yang halus dan jangan terlampau sering karena dapat mempengaruhi keadaan kulit yang sudah kering dan keriput. Manfaat mandi adalah menghilangkan bau, menghilangkan kotoran, merangsang peredaran darah, memberikan kesegaran pada tubuh. 